This is an electronic reprint of the original article. This reprint may differ from the original in pagination and typographic detail.

Please cite the original version: Bogdanova, O. ; Brusila-Meltovaara, K. ; Iso-Aho, J. \& Vuorela, T. (2021) Service Design Experimental Learing in Adult Education, ICERI2O21 Proceedings, pp. 1438-1443.

doi: 10.21125/iceri.2021.0402 


\title{
SERVICE DESIGN EXPERIMENTAL LEARNING IN ADULT EDUCATION
}

\author{
Olga Bogdanova', Kristiina Brusila-Meltovaara', Juha Iso-Aho², Taina Vuorela ${ }^{3}$ \\ ${ }^{1}$ LAB University of Applied Science (FINLAND) \\ ${ }^{2}$ HUMAK University of Applied Science (FINLAND) \\ ${ }^{3}$ Laurea University of Applied Science (FINLAND)
}

\begin{abstract}
Service design has widely been used by companies to enhance their innovation capabilities [1]. In this study, the service design approach was used to enhance companies' innovation capabilities within the cultural and tourism sector in the South Karelia and Uusimaa region in Finland and St. Petersburg area in Russia. Idea generation sessions were set up with the Bachelor students of LAB University of Applied Sciences to provide fresh ideas for the participating companies. As the student innovation suggestions were a preliminary stage in the process, outside experts were later involved to further facilitate idea generation modules. The companies were introduced to the service design methods and were offered online 1-on-1 mentoring sessions with the project experts. The assumption was that the companies faced with the Covid19 crisis would generate and adapt radical innovations. However, the study found that innovations, in general, were incremental rather than revolutionary and were centred around customer satisfaction and the customer path. Using online working sessions to apply service design as a problem-solving tool was also a new approach to the participants. The operational side of the company rather than the radical innovation aspect emerged as the most viable path for the companies to pursue their business activities due to their current lack of human and financial resources.
\end{abstract}

Keywords: Adult education, service design, experiential learning experiments, Innovation, Business model, Online service design workshops.

\section{INTRODUCTION}

Experiential learning is a learning process that involves direct experiences of learners, or " 'learning by doing" [2]. This type of learning is considered effective for adult learning because it involves active experimentation, building on existing knowledge and comparing it with new experiences. Experiential learning is widely used in entrepreneurship education and in professional training programmes as it enables the learning outcomes defined by the European Commission [3] as "converting an idea into reality" or, more specifically, as defined by Hytti and O'Gorman [4], starting own business. The methods of experiential learning widely adopted in adult education include problem-based learning, cooperative learning, and simulations. Problem-based learning (PBL) involves creating a real-world case challenge and placing students in action to solve the problem using their knowledge acquired during the course $[5 ; 6 ; 7]$. The essence of cooperative learning is in developing a learning environment facilitating the exchange of experiences and perspectives between the learners [8]. This learning method is specifically relevant for online learning adult education, where experienced participants value possibilities of discussion and interaction $[9 ; 10]$. Simulations involve developing scenarios with a wide range of alternatives [11] that allow mimicking real-world situations. The experiential learning practices are often associated with group work and creating learning communities.

New product development is a process involving successive progression over the stages from generating entrepreneurial product or service ideas toward launching them in the market [12]. Innovating new business models is the key to SMEs competitive advantage, growth and survival in the market. The exponential growth of digitalisation emphasises the importance of service innovation [13]. The process of new service development outlined by Scheuing and Johnson [14] includes 15 stages, from formulating objectives of new service development to creating concept and market launch and review. The service design approach helps in creating customer-oriented business concepts.

Service research emphasises the ability to envisage customers' future needs and expectations. Service design has established itself as a useful and insightful approach to developing services and services businesses [15]. There are different ways to approach the process of service design, a classical one being the four-phase process [16] of discovery, creation, reality check, and implementation. For more variation on the service design process, see e. g. [17; 18]; scholars have indeed found that service 
design brings new perspectives to SMEs' research, development and innovation activities. Others [19] claim that SMEs are in closer contact with their customers than larger companies; hence, they are innovative and customer-driven in their marketing. However, they may not have all the tools and knowhow for service development; yet it is crucial that business people learn to use design tools to complement their business skills [19]. The scholars [19] also claim that service design co-creation activities via appropriate tools are opportunities both for SMEs and universities in their collaboration; additionally, they emphasise that customers must be integrated into service innovation. It is through the use of the service that the designer experiences the customer's feelings and thinking [20]; thus, the selection of appropriate tools is important.

What is required for successful co-creation activities? According to experts [21], in successful cocreation activities, the necessary prerequisites include: 1 . skilled facilitation, 2 . healthy environment with a clear structure for the work to be undertaken, 3 . diverse team with all acting in the role of active agent, 4. clear needs and pains and communicating about them appropriately, 5. common vision and shared values which create shared ownership, 6 . stakeholder involvement at the right time creates individual roles for individual goals, 7 . handling conflicts and interests through a process and spontaneously, 8. reflection and evaluation. Generally, the co-creation process involves the stages of engaging the participants, understanding their needs and interest, ideating with them, and finally validating the new ideas [21].

Innovation historically has meant a new product, new production methods, new markets, new raw materials or a new marketplace [22; 23]. A key element of innovation is that it can be measured, either through increased revenue, saved costs or an increase in market share. Companies gain a competitive advantage and maintain their market position through being innovative. The key element of survival then seems to be constant innovation - to produce and deliver products and services in a smarter way than the other players in the market - to lean the company processes whilst simultaneously keeping them agile and responsive to market changes [24]. Furthermore, the resilience of organisations is increasingly dependent on their ability to develop their innovation capabilities [25]. One of the main motivators for innovations is obtaining or maintaining a competitive advantage [26]. As the environment companies operate in changes continuously and also often unpredictably, the companies able to adapt or develop gain an advantage, more so the case for those able to predict trends and megatrends [27].

Incremental and radical implementations are two different types of innovation styles an organisation can apply. Radical innovations are breakthrough innovations delivering a creative radical solution to a challenging problem. Incremental innovations provide solutions to a challenging problem [28; 29]. Incremental innovations usually consist of minor enhancements or changes to an existing product concept, service or production technology, which help further differentiate a company from the competition [30; 31; 32; 33].

\section{METHODOLOGY}

This paper employs a qualitative research approach to a case, namely, that of a series of service design workshops within an industry-university collaboration project (EDUCRO, see below for more information about the project). The research question of the study is the following: How can service design be used as an experiential learning method for enhancing innovation capabilities? The benefit of a case study is that it allows generating several perspectives through different accounts of a single method [34] (see Gray 2017); in the present study, this means using the same set of service design business tools to collect data from several company cases within the EDUCRO project. The unit of analysis in the present study is the service design business tool of which we employed four, namely, Business Model Canvas, Customer Profile, Customer Journey and Service Blueprint.

\subsection{Case: EDUCRO training programme}

The cross-border online training programme for culture and tourism professionals was developed by two Finnish higher education institutions (HEI), LAB University of Applied Sciences, Humak University of Applied Sciences (Finland) and the Institute for Cultural Programs (Russia). The essence of the programme was in employing the methods of experiential learning and developing an online participative learning environment enabling concrete learning and developmental outcomes for participants [10]. More specifically, the programme goal was to create "customer value through cross-border collaboration", or, in other words, to facilitate new product or service development in partnerships. The programme structure included six interconnected educational modules which included webinars, group work and discussions, and individual mentoring. 


\subsubsection{Simulation: programme structure as a new product development}

The training programme structure was created to simulate the process of a new product or new service development. The content of the educational modules included sessions dedicated to exploring entrepreneurial opportunities, idea generation, analysing the customers' needs, creating service concepts using service design, developing business models, analysing funding opportunities, learning about marketing and internationalisation of the services. The duration of the training programme was 1 year from September 2020 to September 2021.

At the beginning of the programme, the online networking session was organised as a part of module 1 for the participants of the present study, the adult learners from culture and tourism sectors. This session was aimed at networking, sharing experiences about cross-border collaboration, and analysing the potential for joint new product development. Monthly online networking sessions without agenda were further organised to facilitate networking and discussions. During module 2, participants took part in online sessions, which included an overview of the current and future trends, participated in group discussions aimed at developing new ideas for international services and had individual discussions with the mentor. Module 3 included an analysis of the customer needs of the participant organisations and the exchange of experiences between participants. Based on the customer insight, a service design approach was implemented to create service concepts. Module 4 was dedicated to developing business models from the service concepts and exchange of experiences on various ways of funding projects. Product launch involves the marketing of the services, and during module 5 innovative ways of marketing were discussed during the panel discussions between participants. Finally, during module 6 , the theories of intercultural communication and internationalisation of service SMEs were analysed through the prism of participants own experiences through online in-class discussion.

\subsubsection{Project-based learning: developing new service concepts using the service design approach}

Service design workshops offered for the participating companies of the EDUCRO project were implemented in the form of individual mentoring sessions. In two 90-minutes sessions, each company was advised to analyse and rethink their products, customer profiles and customer journeys with the help of two experts of the project. Six companies, two from Russia and four from Finland, exploited this possibility. Most of the companies were either not familiar with service design methods before the sessions or had some previous knowledge but did not use those methods systematically. A short introductory presentation of the basic concepts of service design was therefore provided at the beginning of the sessions.

Even though the first reactions of the participants to the theoretical framework and terminology of service design might have been somewhat sceptical, all sessions ended with a feeling of positive surprise. Participants found that the tools used were practical and helped to look at their sometimes all-too-familiar functions from a new perspective - that of the customer. Moreover, they realised that they have more assumptions than real knowledge about who their customers are and what their needs are. The most time-consuming part of the sessions was building and analysing the customer journey of the companies. It seemed that it was a revelation for many of them that they would need to consider customers' needs and expectations at so many points of the journey; and that you equally need to know how the processes of the organisation at these points are prepared to meet those needs and expectations as well.

\subsubsection{Problem-based learning: case challenges for the Bachelor students}

During October-November 2020, the problem-based learning sessions were organised for the Bachelor students at LAB University of Applied Sciences in Finland in collaboration with the participants of the EDUCRO training programme. During the first session, two participating companies from Finland introduced their case challenges to the students. The cases were related to the existing operations of the companies, such as improving the existing sales and marketing channels. During the first day, the students developed the first concept of solution and consulted with the representatives of the EDUCRO project. They used the methods of Service Design as a guideline to solve the challenge and developed the final concepts for one month. In November 2020, the students introduced the results to the teachers, project representatives and companies. Some of the students' groups were quite specific in addressing the challenges, while other teams created new service concepts for the companies. The winning team suggested the concept of a new event, which was accepted by the company and they continued collaboration. 


\section{RESULTS}

This section provides the results of the experiential learning interventions. The results were evaluated based on observations, interviews and the feedback collected from participants. The main findings of the analysis of the methods are summarised in Table 1 below.

\subsection{Simulation}

The simulation design of the training programme was beneficial mostly for the participants with concrete developmental plans or projects. According to the feedback from one of the most active participants, they were "very grateful for the opportunity to receive excellent advice from wonderful experts. Without them, it is possible that many moments in the development of the project would have been more difficult, and perhaps we would not have reached some decisions".

\subsection{Project-based learning}

The mentoring sessions offered the companies a glance at the possibilities of service design. It is not possible to predict at this stage whether these sessions will have long-term effects for the participants in the sense that service design tools would be used as part of the everyday innovation practices of the companies. But clearly, the sessions introduced new viewpoints for companies of how they see their customers and the services their offer. In this sense, and largely because the tools presented were new to the participants, the innovations made were more incremental than radical. The structure of the mentoring sessions was probably the best available compromise within the framework of the project and also the time resources of the participants, between a lecture on service design and an extensive service design process. To get more radical results, more meetings with concrete assignments would be needed, including tools that would encourage more radical thinking. And of course, more extensive quantitative and qualitative research of the customer profiles of the companies would be needed.

\subsection{Problem-based learning}

The results of this intervention illustrate that the companies were mainly focused on the operational tasks, while some of the students created new product concepts using the service design methods. Some of the student's ideas were innovative and were considered implementable, for example, guided audio tours for museums; however, they were not incorporated by the companies in their business models.

Table 1. Results of the experiential learning interventions

\begin{tabular}{l|l|l|l}
\hline \multicolumn{1}{c|}{ Method } & \multicolumn{1}{|c|}{ Simulations } & Project-based learning & \multicolumn{1}{c}{ Problem-based learning } \\
\hline Format & $\begin{array}{l}\text { Training programme structure } \\
\text { following new product/service } \\
\text { development stages }\end{array}$ & Service design workshops & $\begin{array}{l}\text { Hackathon using Service design } \\
\text { methods }\end{array}$ \\
\hline $\begin{array}{l}\text { Learning } \\
\text { goals }\end{array}$ & $\begin{array}{l}\text { New service development, } \\
\text { innovations, internationalisation }\end{array}$ & $\begin{array}{l}\text { New service development, } \\
\text { customer-orientation }\end{array}$ & $\begin{array}{l}\text { New service development, } \\
\text { innovations }\end{array}$ \\
\hline Results & $\begin{array}{l}\text { Beneficial for participants with } \\
\text { the ongoing projects }\end{array}$ & $\begin{array}{l}\text { New perspectives and } \\
\text { improved customer } \\
\text { orientation, but no radical } \\
\text { innovations }\end{array}$ & $\begin{array}{l}\text { Innovative solutions suggested by } \\
\text { students but not easily accepted } \\
\text { by participated companies }\end{array}$ \\
\hline
\end{tabular}

\section{CONCLUSIONS}

Innovation capabilities [10] have previously been enhanced by using service design. In this study, service design enhanced companies' innovation capabilities within the cultural and tourism sector in the South Karelia and Uusimaa region in Finland and St. Petersburg area in Russia. Idea generation sessions with the Bachelor students of LAB University of Applied Sciences provided the participating companies with fresh ideas. The ideation was further enhanced by an outside expert to further establish idea generation modules. The participating companies utilised the service design method as well as online 1-on-1 mentoring sessions with the project experts.

The expectation was that the participating companies would generate and adapt radical innovations, particularly when faced with the Covid19 crisis. The study, however, concludes that, in the present case 
study, innovations, in general, were incremental rather than revolutionary. Furthermore, the produced incremental innovations were clustered around customer satisfaction and the customer path, i.e. they were customer-oriented. Service design as a problem-solving tool was a new approach to the participating companies. Customer-focused operational issues, rather than the radical innovation aspect, became the most viable course for the participating companies due to their current insufficient human and financial resources.

\section{REFERENCES}

[1] T. Vuorela, K. Meltovaara, U. Tuominen, O. Bogdanova, "Developing Sustainable Business Management Education in the Cultural sector", 15th International Technology, Education and Development Conference, 2021. Retrieved from DOI: 10.21125/inted.2021.1109.

[2] A.Y. Kolb, D.A. Kolb, "Learning styles and learning spaces: Enhancing experiential learning in higher education", Academy of Management Learning \& Education, Vol. 4(2), pp. 193-212, 2005.

[3] "Green paper on entrepreneurship in Europe", European Commission, 2003. Retrieved from http://ec.europa.eu/enterprise/entrepreneurship/green_paper.

[4] U. Hytti, C. O'Gorman, "What is 'enterprise education? An analysis of the objectives and methods of enterprise education programmes in four European countries", Education Training, Vol. 46(1), pp. 11-23, 2004.

[5] H.S. Barrows, "Problem-based learning in medicine and beyond: A brief overview", New Directions for Teaching and Learning, Vol. 1996(68), 3-12, 1996. Retrieved from http://dx.doi.org/10.1002/tl.37219966804.

[6] J.R. Savery, T.m. Duffy, "Problem-based learning: An instructional model and its constructivist framework", Educational Technology, 35(5), 31-37, 1995.

[7] C. Haas, N. Furman, "Operation recreation, adventure challenge: Teaching programming through problem-based learning theory", Schole: A Journal of Leisure Studies and Recreation Education, Vol. 23, pp. 60-65, 2008.

[8] M. Hamm, D. Adams, "The collaborative dimensions of learning", Norwood, NJ: Ablex, 1992.

[9] N. Furman, J. Sibthorp, "Leveraging Experiential Learning Techniques for Transfer." New directions for adult and continuing education, Vol. 137, pp. 17-26, 2013.

[10] O. Bogdanova, K. Brusila-Meltovaara, L. Janhila, J. Iso-Aho, T. Vuorela, "Cross-border experimental e-learning experiences", 13th annual International Conference on Education and New Learning Technologies, 2021. Retrieved from https://iated.org/concrete3/view_abstract.php?paper_id=89438

[11] K. Hafeez, M. Griffiths, J. Griffiths, M.M. Naim, "Systems design of a two-echelon steel industry supply chain", International Journal of Production Economics, Vol. 45(1-3), pp. 121-130, 1996.

[12] Y.-H. Kim, S.-W. Park, Y.-W. Sawng, "Improving new product development (NPD) process by analysing failure cases", Asia Pacific Journal of Innovation and Entrepreneurship, Vol. 10 No. 1, pp. 134-150, 2016. Retrieved from https://doi.org/10.1108/APJIE-12-2016-002.

[13] A. Vuorio, L. Torkkeli, L.-M. Sainio, "Service Innovation and Internationalisation in SMEs: Antecedents and Profitability Outcomes", Journal of international entrepreneurship, Vol. 18.1, pp. 92-123, 2020. Retrieved from https://doi.org/10.1007/s10843-019-00266-z.

[14] E.E. Scheuing, E.M. Johnson, "A proposed model for new service development", Journal of Services Marketing, Vol. 3 No.2, pp- 25-35, 1989. Retrieved from https://doi.org/10.1108/EUM0000000002484.

[15] S. Miettinen, S. Rontti, E. Kuure and A. Lindström, "Realising Design Thinking through a Service Design Process and an Innovative Prototyping Laboratory: Introducing service innovation corner (SINCO)", in P. Israsena, J. Tangsantikul and D. Durling (eds.), Research: Uncertainty Contradiction Value - DRS International Conference, 1-4 July, Bangkok, Thailand, pp. 1201-1214, 2012. Retrieved from https://dl.designresearchsociety.org/drsconferencepapers/drs2012/researchpapers/89

[16] B. Mager, "Service Design. A Review”, Köln: Köln International School of Design, 2004. 
[17] A. van Oosterom, "Who do we think we are?", in S. Miettinen \& M. Koivisto (ds.), Designing Services with Innovative Methods, pp. 162-179, 2009. Kuopio Academy of Design, University of Art and Design, Helsinki B 93

[18] S. Moritz, "Service Design. Practical Access to an Evolving Field", Köln International School of Design. Cologne: University of Applied Sciences, 2005. Retrieved from http://stefanmoritz.com/welcome/Service_Design_files/Practical\%20Access $\% 20$ to $\% 20$ Service $\% 2$ ODesign.pdf

[19] T. Vuorela, H. Ahola, P. Aro, "Opportunities and Challenges of Using Service Design in SME Service Business Development", in S. Miettinen and A. Valtonen, Service Design with Theory, Rovaniemi: Lapland University Press, 2012.

[20] M. Stickdorn, J. Schneider and co-authors, This is Service Design Thinking. Basics - Tools Cases. Amsterdam: BIS Publishers, 2011.

[21] A. Retegi, B. Sauvage, B. Predan, E. Tomás, G. Schosswohl, M. Kaltenbrunner, D. Draganovská, "The co-create handbook", CO-CREATE consortium. Retrieved from codesign_handbook_FINAL.pdf (cocreate.training)

[22] J. Schumpeter, The theory of economic development, new. ed: Harvard, MA. 1934.

[23] P. Drucker, P. (2014). "Innovation and Entrepreneurship (1st ed.)", Routledge, 2014. Retrieved from https://doi.org/10.4324/9781315747453.

[24] K. Brusila-Meltovaara, Ch. T. Greenan, “Leagile? Leangile?”, LAB Focus, 2020. Retrieved from https://blogit.lab.fi/labfocus/en/leagile-leangile.

[25] R. Rampa, M. Agogué, "Developing radical innovation capabilities: Exploring the effects of training employees for creativity and innovation", Creativity and Innovation Management, Vol. 30(1), pp. 211-227, 2021.

[26] M. E. Porter, "The Competitive Advantage: Creating and Sustaining Superior Performance", NY: Free Press, 1985. (Republished with a new introduction, 1998.) Retrieved from http://www.hbs.edu/faculty/product/193

[27] M. Nupponen, "Cross-sectoral data sharing key to competitive European data markets", Sitra, 2020. Retrieved from https://www.sitra.fi/en/news/cross-sectoral-data-sharing-key-to-competitiveeuropean-data-markets/'

[28] L. Gui, H. Lei, P. B. Le, "Determinants of radical and incremental innovation: the influence of transformational leadership, knowledge sharing and knowledge-centered culture", European Journal of Innovation Management, 2021. Retrieved from https://www.emerald.com/insight/content/doi/10.1108/EJIM-12-2020-0478/full/html)

[29] J.E. Souto, "Business model innovation and business concept innovation as the context of incremental innovation and radical innovation", Tourism Management, Vol. 51, pp. 142-155, 2015.

[30] W. J. Abernathy and K. B. Clark, "Innovation: mapping the winds of creative destruction", Research Policy, 14, pp. 3- 22, 1985.

[31] R. Bouncken.,V. Fredric.,P. Ritala, S. Kraus, "Coopetition in new product development alliances: advantages and tensions for incremental and radical innovation". British Journal of Management, Vol. 29, Issue 3. p. 391-410, 2018. Retrieved from DOI: 10.1111/1467-8551.12213

[32] R. D. Dewar and J. E. Dutton, "'The adoption of radical and incremental innovations: an empirical analysis", Management Science, Vol. 32, pp. 1422-1433, 1986.

[33] J. M. Utterback and W. J. Abernathy, "A dynamic model of process and product innovation", Omega, 3, pp. 639-656, 1975.

[34] D. E. Gray. Doing research in the business world. London: Sage. 2017. 